Fears and hopes of parents in developing the social-emotional aspects of their child with Autism Spectrum Disorder (ASD)

Domalanta, Mary Ann B.

Saint Louis University, Philippines (maryannbarlis69@yahoo.com)

Manching, Mary Joy B.

Saint Louis University, Philippines (manchingmaryjoy@gmail.com)

Manguhan, Regine P.

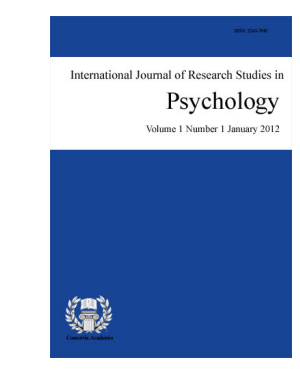

Saint Louis University, Philippines (regina143.rm@gmail.com)

Mapalo, Darleen Joy P.

Saint Louis University, Philippines (darleenjoym@gmail.com)

Marino, Marina V.

Saint Louis University, Philippines (marinamarino6495@gmail.com)

Maxion, Djelyla B.

Saint Louis University, Philippines (Octoberdelta@gmail.com)

Mayam, Julie Rose R.

Saint Louis University, Philippines (julierosemayam15@gmail.com)

\title{
Abstract
}

For every parent, it is known that they have fears and hopes for their child. But to a parent who has a child with Autism Spectrum Disorder, it is likely that their fears are more complicated while their hopes are simple. This study investigates the fears and hopes of parents in developing the social-emotional aspects of their child with autism. The researchers used qualitative method and utilized audio recorders and prepared a questionnaire. Six parents whose child was diagnosed with autism were chosen to be the participants of this study. The study yielded the following concepts: (a) social; (b) survival; (c) security; and (d) strengthening faith. These concepts were derived from the fears and hopes of parents in developing the social and emotional aspect of their child with autism spectrum disorder. Furthermore, a coping mechanism for parents was also explored and named as strengthening faith. This presents enlightening insights on the parents' interchanging fears and hopes.

Keywords: security; social; survival; strengthening faith 


\section{Fears and hopes of parents in developing the social-emotional aspects of their child with Autism Spectrum Disorder (ASD)}

\section{Introduction}

No parent would anticipate having a child with a developmental disability such as autism. Enclosed to the child's diagnosis is a realization that the parent's life will be different than what they had expected it to be. It is likely that they will experience a range of emotions and along with these emotions are their hopes for their children. Hope is shown to provide resiliency for parents of children with Autism Spectrum Disorders (ASDs) against the negative effects related to extreme parenting stressors. The broad positivity of hope may overlook opposing parental feelings about their child that is important for the well-being. Vicarious futurity (VF) is the hope and despair a parent feels for the future of their child, which reflects both positive and negative components of parental attitudes directed toward their child (Faso, Neal-Beevers, \& Carlson, 2013).

At present, "Autism Spectrum Disorder" (ASD) and autism are both general terms for a group of complex disorders of brain development. These disorders are characterized, in varying degrees, by difficulties in social interaction, diet, verbal and nonverbal communication, and repetitive behaviors. Understandably, when a child is diagnosed with autism, concern and support shifts almost entirely from the parent to the child. There is a lack of services available to parents of children with autism. The parents' needs often are not addressed and they are left with few outlets to help them cope with the difficulties of raising a child with autism. Parents of children with autism have few venues to share their stories, experiences, hopes, fears, and needs (Johnson, 2014).

Attached to autism is the triad of impairment (Cashin \& Barker, 2009). They also stated that the triad of impairment has three major components; impairment in imagination, impairment in social communication, and impairment in social relationships. First among these three is the impairment in imagination which includes deficits in flexible thinking regarding interests, routines, perspectives, and rules. A person with autism does not understand other people's point of view or feelings. They are also agitated by sudden changes in routines and they cannot generalize information. They have special interests and they take everything literally. Next to this is the impairment in social communication. This includes deficits in ability to communicate effectively with other people. People with autism ask repetitive questions and 'cannot read between the lines' of what people mean. They only talk about their own interests regardless of the listener's response. They also make factual comments inappropriate to the context and have the absence of desire to communicate. If ever they will communicate, it is only for their own needs and not for social engagement. Lastly, is the impairment in social relationships.

The deficit in this component is in understanding how to behave and interact with other people. People with autism inappropriately touch other people. Along with the deficit is the difficulty in understanding and using nonverbal behavior such as eye contact and facial expressions. They are also unaware of the different ways to interact with peers, staff, or strangers. By all means, they also desire for friendships and relationships but they struggle to initiate and maintain them. The aforementioned, complete the triad and the major components show that communication and socialization is of great importance. The other side of autism is the social-emotional aspect. Social-emotional development includes the child's experience, expression, and management of emotions and the ability to establish positive and rewarding relationships with others (Baron-Cohen \& Belmonte, 2005).

The social development includes the social intelligence. Its original definition dates back in 1920 when it was described by Thorndike as cited in the study of Mayer and Salovey (1993) as "the ability to understand and manage men and women, boys and girls and to act wisely in human relations." The study of Vernon (1933) defines it more precisely as the "ability to get along with people in general, social technique or ease in society, knowledge of social matters, and susceptibility to stimuli from other members of a group, as well as insight into the temporary moods or underlying personality traits of strangers." Moreover, it is emphasized by using the term 
"emotional-social intelligence" which denotes a cross-section of interrelated emotional and social competencies, skills, and facilitators that determine how effectively we understand and express ourselves, understand others and relate with them, and cope with daily demands (Bar-On, 2006). Meanwhile, emotional components include physiological responses and expressions. They play a critical role in regulating important processes including memory, perception, attention, and physical response. Indeed, it is important to handle the social milieu, emotions shape interpersonal interactions, providing information to and about others, evoking emotional responses and reciprocity in others, and shaping others' behaviours toward us. Therefore, emotions are highly important and integrated part of social interaction (Geller, 2005).

As an illustration, emotional facial expressions trigger facial mimicry, even if expressions are observed unconsciously (Dimberg, Thunberg, \& Elmehed, 2000). Since emotional facial expressions are important for promoting social communication and empathy and are often used as stimuli for motor and cognitive empathy (Bons, van den Broek, Scheepers, Herpers, Rommelse, and Buitelaaar, 2013). However, emotional empathy is usually measured in response to distressing or threatening images, as compared to pleasant images. Hence, there are six universal basic emotions that were defined: happy, sad, fear, anger, disgust, and surprise. These basic emotional facial expressions were specified at the muscular level (Bons et al., 2013). Individuals with Autism Spectrum Disorder (ASD) are known to have limitations in social interactions, which have been linked to poor imaginative and social cognitive abilities (Freeth, Ropar, Mitchell, Chapman, \& Loher, 2011).

The ability to regulate one's emotions plays an important role in the socio-emotional development of young children (Calkins \& Mackler, 2011) and because of this, it has been suggested that social stimuli are less salient to individuals with ASD (Jones \& Klin, 2008). Making inferences about mental states and processing others' emotions are often considered to be difficult for individuals with ASD (Baron-Cohen, Ring, Bullmore, Wheelwright, Ashwin, \& Williams, 2000). Children with ASD also tend to spontaneously comment on other's affective states less frequently than typically developing children in everyday conversation (Müller \& Schuler, 2006). They tend to decline, ignore or reject their mothers' social initiatives more often than typical developing children do (Freeth et al., 2011). Children with ASD are also clearly impaired in the ability to share attention to an event, object, or person of mutual interest with an interaction partner as well (Bruinsma, Koegel, \& Koegel, 2004).

On the social-emotional issues for children with autism, bullying is now understood in a much more nuanced light than it used to be. Today, being intentionally ignored, perceptively rejected, or deliberately excluded can feel like bullying as much as outright teasing. When children are bullied at school, parents of children with autism often feel as though they are not protecting their children in an appropriate way. In addition, when children are with their parents, they are not socially anxious. They know the routines. In contrast, at school or in the classroom, they may act socially awkward and seem much more intellectually disabled. When they go home, they might spend hours doing intellectual work on the computer, and they can have an interesting and sophisticated conversation with their parents, but at school, they have trouble talking. This was when a big disconnection happens between parents and teachers. A common perception from the parents was that others tend to judge their children as being "bad" children and beyond that they are bad parents (LePage \& Courey, 2014).

Parents of children with autism are more likely to be stressed than parents of typically developing children with other disabilities, including developmental disabilities (Hirschler-Guttenberg, Feldman, Ostfeld-Etzion, Laor, \& Golan, 2015). The broad positivity of hope may overlook opposing parental feelings about their child and that may be important for well-being. In another study on parental attitudes towards their children, Beurkens, Hobson, and Hobson (2013) defines vicarious futurity as the hope and despair a parent feels for the future of their child. Vicarious futurity reflects both positive and negative components of parental attitudes directed toward their child (Beurkens et al., 2013). The combination of problems with communication and emotional expression in children with ASD is difficult for parents to understand (Gray, Budimirovic, Bukelis, Cox, Tierney, \& Kaufmann, 2006). Children with ASD are often unresponsive, avoid physical contact, and reject parent's 
Domalanta, M. A. B., Manching, M. J. B.,

Manguhan, R. P., Mapalo, D. J. P., Marino, M. V., Maxion, D. B., \& Mayam, J. R. R.

attempts to be affectionate (Altiere \& von Kluge, 2009). Many children with ASD do not want to be touched, held, hugged, nor do they respond to their parent's presence or absence (Volkmar \& Wiesner, 2009).

Most parents believe that their children have great potential and they live up to that potential. These parents are not only proud that their children are successful, but that their children have impressed even them with their openness, their care for others, and their work ethics. They plan to support them as far as they are willing (and able) to go. Another featured discussion or study about the differences between mothers and fathers is that all parents that were interviewed agreed that the mothers seem more concerned about their children's possible future dependency needs than the fathers, and that the fathers expressed more hope that the child would "grow out" of his or her difficulties. Many of the mothers reported that they felt that their husbands or the children's fathers had difficulty coming to terms with the children's diagnoses that initially the fathers were more in denial than they were, thinking that their child is "fine" or needed to "grow up" (LePage \& Courey, 2014).

There are researches that discussed some of the fears and hopes of parents of a child with autism. Unfortunately, specific researches as to what are the fears and hopes of parents in developing the social emotional aspect of their child with autism are limited. In addition, the researchers did not find any available studies that are identical to the topic which is about the fears and hope of parents in developing the social-emotional aspect of their child with autism.

\subsection{Statement of the Problem}

Exploring the attitude of parents in social development and emotional state of their child including the question what if's and why's in their mind. The researchers would like to investigate about the fears and hopes of parents in developing the social-emotional aspect of their child with autism. This research aims to satisfy the following questions:

$>\quad$ What are the fears and hopes of parents for their child with Autism Spectrum Disorder?; and

$>\quad$ How did the parents alleviate their fears?

\subsection{Significance of the Study}

Autism is a developmental disorder characterized by qualitative impairments in social interaction, communication and a restricted range of activities. Individuals with autism have specific impairments in the processing of social and emotional information. Social-emotional development includes the ability to show trust/attachment, empathy, cooperation with other people and self-regulation which were difficult for children with autism to express (Dawson, Meltzoff, Osterling, Rinaldi, \& Brown, 1998). These are some definitions in which parents can easily access in the Internet. However; the result of this study will redound to the benefit of the society considering that the parents have a primary role in the family. This would otherwise raise awareness that parents also have fears and hopes regarding the social-emotional aspect of their child with autism.

Although some researches have shown significant improvement in the development of the social-emotional aspect of children with autism as supported by Mahoney and Perales (2003) it is still difficult for parents to rely solely to these interventions, especially when dealing with their personal stress. But despite these problems, families do cope with autism and often cope successfully (Gray, 2006). To the participants, they would have an assurance that they are not alone in their journey in helping their child. Knowing the fears and hopes of parents in developing the social-emotional aspects of their child with autism would showcase how parents interact or how they face life especially when the society is involved. The researchers would like to be aware of the fears and hopes of parents in developing the social-emotional aspect of their child. In addition, the researchers would like to know the strategies of parents in fulfilling their hopes for their child and how they manage their fears. Altogether, this study will give insights to the fears and hopes of parents to benefit the family members and the researchers. 


\section{Methodology}

\subsection{Participants and Setting}

Six parents, one father and five mothers, whose children were diagnosed with autism within Baguio City (for reason of proximity) were chosen to be the participants of this study. They were chosen based on their availability and willingness to participate.

\subsection{Materials and Procedures}

The researchers employed qualitative phenomenological research design that involves understanding the essence of a prodigy by examining the views of different parents whose child has autism. To achieve and get all the necessary pieces of information about the problem topic, a semi-structured interview was conducted by the researchers (Boyd, 2003). With this, making generalizations was avoided and participants relayed information in details and depth. In the process of gathering data, the researchers used the following key terms: fears, hopes, social-emotional aspect, and autism spectrum disorder. Also, the researchers used audio recorder and prepared questionnaire. The data were collected through personal interviews with the parents of children with autism spectrum disorder based on their availability. The questions were focused on the fears and hopes of parents in developing the social-emotional aspects of their child with autism spectrum disorder. The study was conducted in Baguio City, Philippines, and all information gathered from the participants were kept confidential and for educational purposes only. To capture the essence of the interview, a priori code was used which is a code in qualitative inquiry. It is often a word or short phrase that symbolically assigns a summative, salient, essence-capturing and/or evocative attribute for a portion of language based or visual data. The researchers chose a priori code because this is appropriate for the research. The data consisted of interview transcripts, participant observation field notes, journals, documents, literature, artifacts, and photographs (Yin, 2013).

\subsection{Ethical Consideration}

Written permission was obtained from the Students Affairs Office, Saint Louis University to allow the gathering of data outside the school premises. The purpose and procedure of the study was clearly explained to the participants. The researchers were also keen to ensure that the study was not disruptive to the daily life, works and routines of the participants. The interviews were conducted at a convenient time agreed upon.

\section{Results and Discussion}

Fear as a feeling could be simply manifested as a subjective emotion, a sense of uneasiness, or unconscious perception of some sort of danger or threat (Iqbal, Khawaja, \& Rahman, 2015). Relative to the word fear is worry, it is generally described in relation to future-related anxiety or fear, as opposed in relation to concern regarding past events (Sibrava \& Borkovec, 2006). Parents of children with ASD shows worry for their children that they might develop negative habits that would result to negative effect on their surroundings. Hope is based on the idea that people are goal-oriented. Defined as the perceptions of both agency and pathways, hope is one's belief in the ability to accomplish future goals (Ogston \& Paula, 2011). Hope, as a general language is the desire of something to happen for progress or development. It is a positive attitude of the mind that is merely based on a possibility of positive outcomes. Moreover, hope without anticipation is empty. For this reason, researchers included the question "What do you do to accomplish your dreams in developing the social-emotional aspect of your child with ASD?", within the limitations of this research, for it is said, hope is made up of one's motivation to get things done, as well as the ability to come up with ways to accomplish these goals (Ogston \& Paula, 2011).

With the definitions of fear and hope, the researchers have found out that parents of children with autism spectrum disorder tend to develop their hopes from their fears. Parents alleviate their fears by converting them into hopes. From the qualitative analyses of this study, findings of this narrative inquiry have surfaced an 
Domalanta, M. A. B., Manching, M. J. B.,

Manguhan, R. P., Mapalo, D. J. P., Marino, M. V., Maxion, D. B., \& Mayam, J. R. R.

interesting concept called S-S-S-S which describes the research social, survival, security of fears and hopes of six parents whose children were diagnosed with ASD, as seen in their individual and collective insights and experiences. Hence, strengthening faith is their way to alleviate their fears. The power of qualitative approach in research is indeed a valuable lens in surfacing the multiple layers of meaning embedded in human phenomena (de Guzman \& Tan, 2007). The following are the themes that surfaced from the research:

\subsection{Social}

The first theme is social. It is a progression where in an individual familiarizes to fiddle with a group or society and perform in a manner accepted by the group or society. Social means relating to or involving in activities in which people spend time talking to each other or doing enjoyable things. However, parents of children with autism have fear that their child can not spend time talking or doing enjoyable things. According to Ergenecon, (2012), individuals with developmental disorder have difficulties in giving information to their parents about the negative events that they face. Like what was said by participant number 6 (February 26, 2016), "I am afraid that he will not learn how to socialize with other people like in school where he has no friends". Also, the same participant said (February 9, 2016), "Because he barely spoke, definitely, he cannot answer the questions addressed to him." But according to Eissa (2015) language difficulties commonly occurring within the spectrum include using only nonverbal forms of communication, having delayed speech, participating in the use of echolalia, using only single words to communicate, and exercising other abnormalities in the use of language. These difficulties often contribute to many of the behavioral issues observed in ASD because the individuals become frustrated with the task of trying to portray the appropriate message to others.

One of the major diagnostic criteria associated with Autism Spectrum Disorder focuses on impairments in communication development (Eissa, 2015). Participant number 3 (April 2, 2016) stated that "He cannot speak. When you call him he does not respond. He appears to be snobbish. He does not reply when you call for him." In addition, participant number 2 (April 6, 2016) narrated that "Additionally, my fear in social-emotional aspect is when he will be having his OJT when he will be second year. How will he interact with other people? Will they understand him?" In the context of ASD, deficits accompanying the development of communication skills involve both the spoken and written word (Autism Society of America, 2006).

In the analysis of this study, the fear of parents in the socialization of their children was made simple that their child would not be able to express their feelings and wants to other people without the help of the parents or caregivers, to communicate with peers properly such as on how to react appropriately and/or to involve themselves with other children in such situations. But through these fears comes their hopes for their children. "By comparison, mothers with children with autism mostly spoke of the problems with their children messing up houses or damaging objects in the houses. They made no mention of problems resulting from behaviors inappropriate for the ages of their children." A statement from Tayyare, Akçin, Fakultesi, Bolumu, and Kampusu (2013) is parallel to the statement of one of the respondents. As stated by participant number 1 (February 4, 2016) "He will interact with other people, good he interacts with his family members. I hope he develops patience along with his communication skills he can say what he wants, what is painful, what he doesn't like, and what he feels."

On the other hand, participant number 2 (April 6, 2016) said that "The problem is how to start a conversation. That alone is a problem to him." Furthermore, participant number 3 (April 2, 2016) responded, "I wish he is expressive because he is verbal although he does not do everything he wants and he is echolalic that's why sometimes instead of saying what he wants, he will just point it, then I will ask him, what will you say?" Severity levels of difficulties with social communication on the one side and severity level of fixated or repetitive and restricted behaviors or interests on the other (Ozerk, 2016). It was also related to the statement of one of the respondents in the study of Tayyare et al. (2013) in which the mother said "I ask her about it when something happens, she says she did not do it, but she fails to explain what happened. People say that it was Begüm who did it, but she says that she did not do it, others gang up on her, and she cannot defend herself 
(Interview \#23; 7/10, p.10)."

True enough, the parents positively look forward that their children are able to say how they feel and what they want to do. Mothers indicated concerns regarding their children's social adjustment. They question whether or not their child would ever have real friends or romantic relationships. Some respondents wondered whether their child would have a happy life Ogston et al. (2011). Like most of the parents, they wanted to train their child with autism on how to communicate well and to build a stronger relationship with other people. As said by participant number 2 (April 6, 2016) "As early as now he should be exposed independently. When he meets other people often, he can communicate accordingly, but isn't it that when we talk to other people it is where you get the next topic of your conversation?" Moreover, participant number 4 (April 4, 2016) said that, "In the emotional aspect, hopefully his emotions would be stable, his emotions and actions will be appropriate with his age. In the social aspect, hopefully he will become normal that he will be able to socialize with people of his age." Furthermore, participant 5 (February 26, 2016) described "In socialization, hopefully he will be able to mingle with visitors." In fact, participant number 6 (February 9, 2016) said that, "Hopefully, he will learn everything I teach him most especially self-care and mingling with other people." The study conducted by Eissa (2015) shows that joint attention intervention was effective in improving eye contact, gesturing, follow the instructions, initiating caressing/singing (joint attention subscales) and communication skills of all children participated in this study. This study also shows that parents' anticipation regarding their child is directed toward the attainment of their social skills.

Accordingly, children with autism have difficulties in communication skills so they need to be exposed through communicating with other people. It is also considered to be one of the primary problems of the parents. The study by Dykstra, Boyd, Watson, Crais, and Baranek (2011) cited that preschool children with ASD have difficulties with social-communication and play skills that reflect the core features of the disorder. As supported by the research statement of Tayyare et al., (2013) he says that "As with the education provided for all children, education for handicapped children aims to allow them to continue their lives without depending on others and to become self-sufficient in the future."

Indeed, social skills such as verbal communication, self-expression, and play are necessary for children to have in order for them to cope with daily activities. Not only are these skills a necessary part of participation in a preschool classroom, but they also are related to concurrent language skills and are predictive of later language abilities, adaptive functioning, and academic performance. Dykstra et al. (2002) also added that, such findings have led to hypotheses that early social-communication and play behaviors represent pivotal skills that have positive, cascading effects on other learning areas (Kasari \& Rotheram-Fuller, 2005).

Generally, the ability to communicate effectively is necessary for daily living activities, just like the aforementioned. And according to researches, limited mental process, skills, poor language development, and unusual or inappropriate behaviors of children with mental disabilities and autism prevent them from interacting with others to a considerable extent (Tayyare et al., 2013). Hence, the hope of parents in developing the social and emotional aspect of their child with autism should be fulfilled. For it is said that social skills and play are predictive of later language abilities, adaptive functioning, and academic performance (Dykstra et al., 2011). To simplify it, social skills are considered to be a survival skill for it is being used in everyday life.

\subsection{Survival}

The second theme is survival. This is the ability to continue to live or exist especially in spite of difficult conditions with or without the help of others. Children with autism learn daily living skills because it is more important than academic skills and they are essential in preparation to adulthood (Sarris, 2014). Parents of children with Autism Spectrum Disorder strive to find ways for their children's survival. From the parent's perspective in the ability of their child to do basic daily living skills like eating, taking a bath, and personal necessities worries have aroused. In addition to that, most of the parents' fear that their child might not be able to 
Domalanta, M. A. B., Manching, M. J. B.,

Manguhan, R. P., Mapalo, D. J. P., Marino, M. V., Maxion, D. B., \& Mayam, J. R. R.

maintain their personal hygiene, like using a napkin and washing after defecating. In fact, it is one of the most important skills to be taught to them. Parents are looking forward to teach their child and to instill in their mind the how to of personal hygiene and teaching them the skills which are essential for them to live as a part of the society as independent as possible (Ergenecon, 2012). Like what has been stated by participant number 1 (February 4, 2016) "That she will grow up without learning for example, she has menstruation but she does not know how to use napkin."

More than the fear of merely not being able to change sanitary napkins is the consequences of it to their child's health. Poor protection and inadequate washing facilities may increase susceptibility to infection, with the odor of menstrual blood putting girls at risk of being stigmatized (House, Mahon, \& Cavill, 2012; Kirk \& Sommer, 2006). This would imply that the fear that the parents identified would likely result to another fear when it is not addressed immediately. In addition, participant number 6 (February 9, 2016) said, "One more thing that I fear is that he might not learn to deficate and urinate on his own." Related to that, participant number 5 (April 26, 2016) "Also, I am afraid that he would not learn to brush his teeth on his own."

Furthermore, life skills allow students to deal with current and future day-to-day demands and responsibilities (Tayyare et al., 2013). For a parent whose child is not yet capable of taking care of himself is really something to worry about. Likewise, parents silently wish that their children would be able to do things on their own. As participant number 5 (April 26, 2016) said "For him to at least eat on his own and refrain spilling food on the table." Similar to what has participant number 5 said, participant number 4 (April 4, 2016) and participant 1 (February 4, 2016), "Hopefully, she will be able to eat on her own."

Indeed, to a parent whose child is not yet well-trained to be independent in eating, parents hope that their child would not sleep with an empty stomach because they perceive it to trigger for more complex illness. Raising a child who has special needs can at times affect parents in ways that cause them to worry and wonder what their future will hold (Iannielli, 2016). As presented above, the parents wanted their children to be in a good condition in a way that they eat right on their own and do their personal hygiene by themselves. These are hopes for the parents, hopes which are their simplest sense of great achievement for a child with autism as it will help them survive in day-to-day encounter. As supported by Crow (2017), children with disabilities of every kind need to learn hygiene and self-help skills as soon as they are able. These skills should be taught from the time the child is very young, because the sooner and in more ways the child can become independent.

\subsection{Security}

The third theme is security. The connection of security of their child to this research is to unravel the parents' fears and hopes in the social and emotional aspects of their child with ASD. Buzan (1991) defined security as a pursuit of freedom from threats. It is one of the common fears of parents in developing children with ASD in social-emotional aspect. Notably, security is the sense of peace and fulfillment of parents of children with ASD that their children's sense of independence in expressing themselves through actions and communication is important. Most of our respondents have proven this to be true.

One aspect of security that was pointed out by one of the parents is the bi-conditional bullying. These talks about the children with ASD being bullied or be the one bullying. According to the study of Woods, Mahdavi, and Ryan (2013), awareness of bullying and the noted high prevalence in individuals with ASD is of particular concern, since more people are being diagnosed with ASD than ever before. It is evident that people who are different or who are perceived to have deficits seem to be more susceptible to bullying. It is not surprising that bully victimization in individuals with ASD is particularly highly estimated. As described by participant number 2 (April 6, 2016), "My fear is that my child would not be able to determine whether other people are just playing around or he is already being bullied because he gets mad if that is the case."

Under these circumstances, the parent wants their son to determine whether he is being bullied or vice versa. Likewise, the parent hopes that their child would be able to determine the proper ways to communicate with 
Fears and hopes of parents in developing the social-emotional aspects of child with Autism Spectrum Disorder others. She even reiterated that what they want for their son is, "That he will achieve appropriate emotion even if he is alone and when he is having a conversation with someone and he is properly communicating."

Aside from bullying, the researchers found out that parents are worried of who will take care of their children when they are gone. This is one of the issues on fears of parents in having a child with ASD. The researchers asked the parents what their fears are in developing the social and emotional aspects of their child and these are the responses of participant number 3 (April 2, 2016) "I also have the fear that, what if I will be gone?" As the aforesaid, the fear of the parent is what if she dies first, while the mother's hope is, "That is why I am requesting and praying that if possible he would die before me and I am informing his brothers that they should take care of him and accept their brother for what he is and what he is capable of." Additionally, participant number 5 (February 26, 2016) said, "Who will take care of him in the future?" However, the parent hopes that "His older siblings is seeking for a partner that would like him and willing to take care of him."

Above all, the parents with children with ASD indeed, have the anxiety of losing their lives first before their children due to the fact that they could not imagine how the life of their children be after the parents die. Likewise, participant number 6 (February 9, 2016), "The parent fears that when he dies what will happen to his child." Despite the fear of the parents, they hope that, "That it is better if we both die so that we would be both at peace especially on the part of the parent knowing that no one can hurt his child anymore because they are both dead." For the reason that the parents have burden in taking care of their children with ASD, they most likely want to die together with their child than being the first to be gone. As what was also stated in the study of Ogston, Mackintosh, and Myers (2011), mothers worry about what would happen to their children when they die. Some mothers' express concern that no one will take care of their child as well as they were able when they are alive.

In the same way, communication is one of the fears of parents that they wanted to secure that their children can interact effectively in society. Due to the fact that parents do also have fear that when they die first they do not know who would take care and who would support their children's needs. As what was stated in the triad of ASD, children with autism include deficits in the ability to communicate well with other people. Similarly, in the study of Baron-Cohen, and Frith (1985), theory of mind deficits is evident in children with autism. They have difficulty in understanding others' thoughts, mental states, desires, and intentions, which is believed to be responsible for their poor social communication skills Baron-Cohen (2000). As narrated by participant number 1 (February 4, 2016), "She grew up not being able to say what she wants." The foregoing statement is the fear of the parent, while in the other hand, the parent hope is "because we want her to say the things that she wants."

When children with ASD grow up and mature in age, their parents' worry seem to grow as well in terms of communication in the sense that their children would not still be able to express what they need and what they want. As stated by participant 2 (April 16, 2016), "And the thought that people would not be able to understand the child because of the manner of communication which is different is the fear of the parent." Seemingly, it is a fear of the parents that people around might not be able to understand their children with ASD since such children have a different way of socializing and communicating. Another hope of parent for her child is "I hope that he will find a friend who will be able to understand him and the things that he wants to say." According to the study of Ogston, Mackintosh, and Myers (2011), mothers indicated concerns regarding their children's social adjustment. They questioned whether or not their child would ever have real friends or romantic relationships. Indeed, the parents hope that her child would have a friend that can fully understand him.

To sum up, the researchers found that in terms of security of parents in developing the social-emotional aspect of their children with ASD, bi-conditional bullying, caregivers' availability when parents are gone and communication are common. The similarities of the responses of parents made the researchers envisage the difficulty of parents endlessly pondering the possibilities of what could happen on their child with ASD when they are not around or maybe when they are gone. To think that their child with ASD has siblings, parents are still vulnerable for what might happen in the future. Remarkably, parents will always love their child 
Domalanta, M. A. B., Manching, M. J. B.,

Manguhan, R. P., Mapalo, D. J. P., Marino, M. V., Maxion, D. B., \& Mayam, J. R. R.

unconditionally no matter what happens.

\subsection{Strengthening faith}

Strengthening faith is the intensifying beliefs in God. In accordance with the Bible, faith is the assured expectation of things hoped for (Hebrew 11:1). In alleviating the parents' fears for their children with autism spectrum disorder, parents turned into feeding their spiritual strength. They perceived that strengthening the bond between them and the CREATOR will guide them rearing and coping with their fears. In addition, parents of children with autism find relief by actively participating in church activities. Additionally, they find it helpful in comforting themselves. As participant number 5 has narrated, "The presence of a church is a big deal, of course it is like being guided by faith and believing that God will lead you the way." Similarly, participant number 4 (April 4, 2016) said that, "Indeed, my church mates helped me a lot because the burden in my heart was heightened."

As a coping strategy, the parents turn to a stronghold of their faith in God. Several families, although without professional guidance, appeared to have developed coping strategies similar to the adaptive approaches of positive re-appraisal or confirmation as described by Myles, Dunn, Rinner, Hagiwara, Reese, Huggins, and Becker (2004). Also, participant number 3 said, "Another one is prayer most especially when I am down." As what has transpired in the interview, all of the parents believed that prayer is indeed a powerful tool that helped them to survive with their struggles in raising their child with ASD. As Bronfenbrenner (1979) has stated, faith and belief in God plays an important role in reduction of stress and can be used as a tool for recovery by parents with disabled children. It surfaced in the interview that parents undergo stress in taking care of their child with Autism Spectrum Disorder (ASD). As explained, it is evident in parents that praise and worship is the proper outlet for them to ease their stress. Relatively, parents hope that their children would be safe all the time as much as possible.

\section{Conclusion}

For every parent, it is known that they have fears and hopes for their child. But to a parent who has a child with autism spectrum disorder, it is likely that their fears are more complicated while their hopes are simple. As a matter of fact, their fears were the determinants of their hopes, because when parents identify their fears for their child, they subsequently pair it with a hope. To illustrate, if the parent narrates her fear that the child might be bullied, the parent will end her statement with "I hope not." This implies that if you have fear, it automatically follows a hope. It is natural for these parents to have worries and fears because it is innate for individuals with Autism Spectrum Disorder (ASD) to have deficits in many areas namely; normal social interaction, communication, and independent daily functioning.

In accordance to that, parents also developed their own strategy to cope with their situation by submitting their fears and hopes to the Lord. For these parents, rendering regular service to the religious institutions where they belong is an outlet for them to be comforted and to ease their stress. In this case, their faith is being strengthened. Along with the identifications of the parents' fears and hopes in developing the social and emotional aspect of their child with autism, it materialized that having little knowledge or no knowledge at all about the case of your child being the parent, Interventions necessary for his development will be delayed. For this reason, it will complicate the child's situation. Interestingly, upon singling out the three components of the fears and hopes, particularly in the security, there came out a concept called bi-conditional bullying. This concept was placed under the fears of parents. It is a concept wherein, the parent fears that the child might be bullied or vice versa, the child might be a bully.

\subsection{Recommendation}

The following recommendations are offered for future research direction: (a) Provided the Fears and Hopes of Parents in Developing the Social and Emotional Aspects of Their Child with Autism Spectrum Disorder (ASD) 
Fears and hopes of parents in developing the social-emotional aspects of child with Autism Spectrum Disorder in the Philippines specifically in Baguio City, would it be that the Fears and Hopes of Parents whose children are diagnosed with ASD from remote places in the Philippines be the same and thereby have a similar coping mechanisms. (b) Given that this study provides a basis for parents to cope with their fears in developing the social and emotional aspects of their child with ASD, defining how their coping mechanisms can relief them would prove to be valuable. Such an effort would enable other parents whose child has ASD and or Disability to pattern their coping mechanisms from a research base.

\section{References}

Altiere, M. J., \& von Kluge, S. (2009). Family functioning and coping behaviors in parents of children with autism. Journal of Child and Family Studies, 18(1), 83-92. https://doi.org/10.1007/s10826-008-9209-y

Bar-On, R. (2006). The Bar-On model of emotional-social intelligence (ESI). Psicothema, 18, 13-25.

Baron-Cohen, S., \& Belmonte, M. K. (2005). Autism: A window onto the development of the social and the analytic brain. Annual Review Neuroscience, 28, 109-126. https://doi.org/10.1146/annurev.neuro.27.070203.144137

Baron-Cohen, S., Leslie, A. M., \& Frith, U. (1985). Does the autistic child have a "theory of mind"? Cognition, 21(1), 37-46. https://doi.org/10.1016/0010-0277(85)90022-8

Baron-Cohen, S., Ring, H. A., Bullmore, E. T., Wheelwright, S., Ashwin, C., \& Williams, S. C. R. (2000). The amygdala theory of autism. Neuroscience \& Biobehavioral Reviews, 24(3), 355-364. https://doi.org/10.1016/S0149-7634(00)00011-7

Beurkens, N. M., Hobson, J. A., \& Hobson, R. P. (2013). Autism severity and qualities of parent-child relations. Journal of Autism and Developmental Disorders, 43(1), 168-178. https://doi.org/10.1007/s10803-012-1562-4

Bons, D., van den Broek, E., Scheepers, F., Herpers, P., Rommelse, N., \& Buitelaaar, J. K. (2013). Motor, emotional, and cognitive empathy in children and adolescents with autism spectrum disorder and conduct disorder. Journal of Abnormal Child Psychology, 41(3), 425-443.

https://doi.org/10.1007/s10802-012-9689-5

Boyd, N. (2017). Phenomenological design: Definition, advantages \&limitations. Retrieved from http://study.com/academy/lesson/phenomenological-design-definition-advantages-limitations.html

Bruinsma, Y., Koegel, R. L., \& Koegel, L. K. (2004). Joint attention and children with autism: Areview of the literature. Mental Retardation and Developmental Disabilities Research Reviews, 10(3), 169-175. https://doi.org/10.1002/mrdd.20036

Buzan, B. (1991). New patterns of global security in the twenty-first century. International Affairs (Royal Institute of International Affairs), 19(44), 431-451. https://doi.org/10.2307/2621945

Calkins, S. D., \& Mackler, J. S. (2011). Temperament, emotion regulation, and social development. Social Development: Relationships in Infancy, Childhood, and Adolescence, 44-70.

Cashin, A., \& Barker, P. (2009). The triad of impairment in autism revisited. Journal of Child and Adolescent Psychiatric Nursing, 22(4), 189-193. https://doi.org/10.1111/j.1744-6171.2009.00198.x

Crow, K. (2017). Teaching your young child specific self-help skills special needs. Retrieved from https://www.families.com/blog/teaching-your-young-child-specific-self-help-skills.

de Guzman, A. B., \& Tan, E. B. (2007). Understanding the essence of scholarship from the lived experiences of a select group of outstanding Filipino researchers. Educational Research Journal, 22(1), 49-68.

Dimberg, U., Thunberg, M., \& Elmehed, K. (2000). Unconscious facial reactions to emotional facial expressions. Psychological Science, 11(1), 86-89. https://doi.org/10.1111/1467-9280.00221

Dykstra, J. R., Boyd, B. A., Watson, L. R., Crais, E. R., \& Baranek, G T. (2012). The impact of the advancing social-communication and play (ASAP) intervention on preschoolers with autism spectrum disorder. Autism, 16(1), 27-44. https://doi.org/10.1177/1362361311408933

Eissa, M. A. (2015). The effectiveness of a joint attention training program on improving communication skills of children with autism spectrum disorder. Online Submission, 4(3), 3-12.

Ergenekon, Y. (2012). Teaching basic first-aid skills against home accidents to children with autism through video 
Domalanta, M. A. B., Manching, M. J. B.,

Manguhan, R. P., Mapalo, D. J. P., Marino, M. V., Maxion, D. B., \& Mayam, J. R. R.

modeling. Educational Sciences: Theory and Practice, 12(4), 2759-2766.

Faso, D. J., Neal-Beevers, A. R., \& Carlson, C. L. (2013). Vicarious futurity, hope, and well-being in parents of children with autism spectrum disorder. Research in Autism Spectrum Disorders, 7(2), 288-297. https://doi.org/10.1016/j.rasd.2012.08.014

Freeth, M., Ropar, D., Mitchell, P., Chapman, P., \& Loher, S. (2011). Brief report: How adolescents with ASD process social information in complex scenes combining evidence from eye movements and verbal descriptions. Journal of Autism and Developmental Disorders, 41(3), 364-371. https://doi.org/10.1007/s10803-010-1053-4

Geller, L. (2005). Asperger center for education and training emotional regulation and Autism Spectrum Disorders. Retrieved from http://aspergercenter.com/articles/Emotional-Regulation-and-Autism-Spectrum.pdf

Gray, R. M., Budimirovic, D. B., Bukelis, I., Cox, C., Tierney, E., \& Kaufmann, W. E. (2006). Autism spectrum disorder in fragile $\mathrm{X}$ syndrome: Differential contribution of adaptive socialization and social withdrawal. American Journal of Medical Genetics Part A, 140(17), 1814-1826.

Hirschler-Guttenberg, Y., Feldman, R., Ostfeld-Etzion, S., Laor, N., \& Golan, O. (2015). Self- and co-regulation of anger and fear in preschoolers with autism spectrum disorders: The role of maternal parenting style and temperament. Journal of Autism and Developmental Disorders, 45(9), 3004-3014. https://doi.org/10.1007/s10803-015-2464-z

House, S., Mahon, T., \& Cavill, S. (2013). Menstrual hygiene matters: A resource for improving menstrual hygiene around the world. Reproductive Health Matters, 21(41), 257-259.

Iannielli III, E. D. (2016). Autism \& a parent's expectations: Autism Support Network. Retrieved from http://www.autismsupportnetwork.com/news/autism-parents-expectations-34728942.

Iqbal, F., Khawaja, G., \& Rahman, M. K. (2015). Understanding empathy with reference to Rumi. Asian Journal of Social Sciences \& Humanities, 4, 4.

Johnsons, K. C. (2014). A journey into our world: A look on parents'perspective on an autism diagnosis (Unpublished doctoral dissertation). Westminster College, Salt Lake City, Utah.

Jones, W., Carr, K., \& Klin, A. (2008). Absence of preferential looking to the eyes of approaching adults predicts level of social disability in 2-year-old toddlers with autism spectrum disorder. Archives of General Psychiatry, 65(8), 946-954. https://doi.org/10.1001/archpsyc.65.8.946

Kasari, C., \& Rotheram-Fuller, E. (2005). Current trends in psychological research on children with high-functioning autism and Asperger disorder. Current Opinion in Psychiatry, 18(5), 497-501. https://doi.org/10.1097/01.yco.0000179486.47144.61

Kirk, J., \& Sommer, M. (2006). Menstruation and body awareness: linking girls' health with girls' education. Royal Tropical Institute (KIT), Special on Gender and Health, 1-22.

LePage, P., \& Courey, S. (2013). Teaching children with high-level Autism: Evidence from families. New York City: Routledge.

Mahoney, G., \& Perales, F. (2003). Using relationship-focused intervention to enhance the social-emotional functioning of young children with autism spectrum disorders. Topics in Early Childhood Special Education, 23(2), 74-86. https://doi.org/10.1177/02711214030230020301

Mayer, J. D., \& Salovey, P. (1993). The intelligence of emotional intelligence. Intelligence, 17(4), 433-442. https://doi.org/10.1016/0160-2896(93)90010-3

Monnier, M. (2015). Difficulties in defining social-emotional intelligence, competences and skills-a theoretical analysis and structural suggestion. International Journal for Research in Vocational Education and Training, 2(1), 59-84.

Müller, E., \& Schuler, A. (2006). Verbal marking of affect by children with Asperger syndrome and high functioning autism during spontaneous interactions with family members. Journal of Autism and Developmental Disorders, 36(8), 1089-1100. https://doi.org/10.1007/s10803-006-0146-6

Myles, B. S., Dunn, W., Rinner, L., Hagiwara, T., Reese, M., Huggins, A., \& Becker, S. (2004). Sensory issues in children with Asperger syndrome and autism. Education and Training in Developmental Disabilities, 283-290. 
Fears and hopes of parents in developing the social-emotional aspects of child with Autism Spectrum Disorder

Ogston, P. L., Mackintosh, V. H., \& Myers, B. J. (2011). Hope and worry in mothers of children with an autism spectrum disorder or down-syndrome. Research in Autism Spectrum Disorders, 5(4), 1378-1384. https://doi.org/10.1016/j.rasd.2011.01.020

Ozerk, K. (2016). The issue of prevalence of autism/ASD. International Electronic Journal of Elementary Education, 9(2), 263-306.

Sarris, M. (2014). Coming of Age: Autism and the transition to adulthood: Interactive autism network. Retrieved fromhttps://iancommunity.org/ssc/autism-transition-to-adulthood.

Sibrava, N. J., \& Borkovec, T. D. (2006). The cognitive avoidance theory of worry. Worry and its Psychological Disorders: Theory, Assessment and Treatment, 239-256.

Tayyare, B. Ç., Akçin, N., Fakultesi, A. E., Bolumu, O. E., \& Kampusu, G (2013). The difficulties encountered by the mothers having children with mental disabilities or autism in participating to community life. International Journal of Special Education, 28(2), 123-135.

Vernon, P. E. (1933). Some characteristics of the good judge of personality. Journal of Social Psychology, 4, $42-57$. https://doi.org/10.1080/00224545.1933.9921556

Volkmar, F. R., \& Wiesner, L. A. (2009). A practical guide to autism. Hoboken, NJ: Wiley.

Woods, A. G., Mahdavi, E., \& Ryan, J. P. (2013). Treating clients with Asperger's syndrome and autism. Child and adolescent psychiatry and mental health, 7(1),32. https://doi.org/10.1186/1753-2000-7-32

Yin, R. K. (2013). Case study research: Design and methods. Thousand Oaks: Sage publications. 
Domalanta, M. A. B., Manching, M. J. B.,

Manguhan, R. P., Mapalo, D. J. P., Marino, M. V., Maxion, D. B., \& Mayam, J. R. R. 